\title{
Tactical Approach for Developing Students' Understanding in Football Learning
}

\author{
Sucipto Sucipto*, Oom Rohmah, Agus Gumilar and Burhan Hambali \\ Physical Education Department \\ Universitas Pendidikan Indonesia \\ Bandung, Indonesia \\ *sucipto@upi.edu
}

\begin{abstract}
- this study aims to examine the application of tactical approaches in developing understanding of junior high school football student learning. The method used in this study is a quasi-experimental design with pre-test post-test control group design. Involves two groups, namely one experimental group with a tactical approach intervention and one group with a technical (traditional) approach. The instrument used in this study is a multiple choice cognition instrument at the level of difficulty $\mathrm{C} 1$ to $\mathrm{C3}$ which is used to measure students' understanding in learning to play football. The study was conducted on junior high school students in the city of Bandung. All data obtained was analysed using the independent sample $t$ test technique with the aim to see the effect of the tactical approach in developing students' understanding of football learning. The results of the analysis show that there are significant differences between the average understanding of football learning using the tactical approach and the technical approach. This is evidenced by the results of pvalue of $0.002(0.002<0.05)$. Thus it can be concluded that the tactical approach can influence the development of student understanding in football learning.
\end{abstract}

Keywords: tactical approach, understanding, football learning

\section{INTRODUCTION}

The main issue that becomes a challenge for physical education teachers is their poor professionalism which has resulted in physical education teachers not being seen as professional expertise. Physical education in schools has not yet evoked the expected learning process in accordance with curriculum objectives so that the field of physical education studies is still considered to be less useful compared to other fields of study.

The Indonesian Ministry of National Education explains that Sports, Health and Physical Education is an integral part of education as a whole. The aims of Sports, Health and Physical Education are to develop aspects of physical fitness, movement skills, critical thinking skills, social skills, reasoning, emotional stability, moral actions, aspects of healthy lifestyle and introduction to environmental cleaning through selected sports, health and physical activities that are systematically planned to achieve national education goals.

In most cases, physical education teachers focus their learning solely on the aspect of skills accomplishment or aspects of achievement in sports, thus ignoring other aspects such as cognitive and affective. Therefore, the curriculum targets that should be developed the three aspects of physical education learning such as cognitive, affective, and psychomotor are not optimally achieved. This will have some impacts on physical education learning such as students who do not feel comfortable and forced to contribute in class, are bored or come to the class merely to fulfil their presence. Sometimes students get annoyed and bored with having to wait for too long to get their turn to do the physical activities instructed by the teacher in physical education learning. L. Brown \& Grineski stated that the phenomenon in physical education nowadays is that many children are reluctant to take physical education lessons because it seems boring and tedious [1]. There are several physical education teachers who in the physical education learning process make the student feel anxious and frightened to the extent where scores are used as a form of threat to make them willingly follow physical education learning. Whereas Prochaska, Sallis, Slymen, \& McKenzie are revealed that one of the physical education missions (PE) is to promote students' participation in exciting physical activities [2].

Learning approaches that are often applied by teachers in learning physical education, especially game activities such as football, is generally technical and tactical. This was revealed by Griffin et al that in implementing game-based learning, there are two models of approaches: (1) technical approach, and (2) tactical approach [3]. Both of these approaches are equally geared towards the game. The difference between the two approaches lies in the stages of learning.

The technical approach prioritizes the skills before starting a game. The technical approach is a skills learning approach that emphasizes the mastery of basic techniques first before dealing with the techniques of the playing patterns [3]. While the tactical approach emphasizes the understanding of the concept of play before the playing actual game, techniques are taught based on the needs in the game. The tactical approach model is a game-based learning model that aims to increase student awareness regarding the concept of play through the application of appropriate techniques according to problems or situations in the game [4].

According to Werner, Thorpe, and Bunker, the tactical approach is a learning model using game situations in which there are problems related to game tactics with a certain level of difficulty [5]. Mitchell stated that the tactical approach is directed at improving the ability to play games by integrating technical skills and understanding of tactics and encouraging 
students to appreciate the values of skills in the context of the game [6].

Concerning the interest in learning football, Grifin et al., Explained the benefits of using tactical approaches as follows [4]:

- Mastering the ability to play through the relationship between tactical and game development.

- Providing enjoyment through various activities.

- Able to solve problems and make immediate and correct decisions in play.

- Increase tactical awareness of students about the concept of play through the application of appropriate techniques according to the problem or situation in the real game.

Grifin, Mitchel, \& Oslin also added that learning the game through a tactical approach will gain excitement and motivation [4]. Likewise, Gubacs-Collins explains in the perspective of teaching, the tactical approach has two main assumptions namely (1) made to increase greater interest and excitement for students, (2) increase tactical knowledge and playing skills for all students [7]. Furthermore, Grifin et al., explained "the technical approach leans on the traditional approach in teaching games which does not stimulate students' interest to learn, let alone improving their ability to play [3]. That statement is supported by Prochaska et al., that the missions of physical education (PE) is promoting students' participation in enjoyable physical activities [2].

From the description above, important questions are raised when there are obstacles in playing caused by poor technique mastery in the game and also to detect students' understanding in following the game.

Given the importance of developing students' understanding of learning football where the learning activity is often tedious and less effective, it is necessary to find new models that can facilitate students in understanding football games. Quoted from previous research statements that tactical learning has the potential to be a model that can enhance students' understanding, it is necessary to conduct research on this tactical learning approach for junior high school students.

\section{METHOD}

The research method used in this study was experimental with Pre-test Post-test Control Group Design. The use of the experimental method is assumed because basically, the main objective in this study is to find out the effect of tactical approach on the interest in learning football. In this research, there will be two groups as the subjects.

The participants of this study were junior high school students in Bandung with cluster random sampling technique that refers to two sampling techniques namely random selection and random assignment - it is based on research needs that require facilities and infrastructure which specifically related to football learning in particular schools that will become research site. The subjects used in this study were 56 students divided into 28 male students and 28 female students.

\section{A. Comprehension Test and Analysis of Football Games}

To measure the level of students' ability to understand and analyse football games, measurements through tests are used by giving questions about playing football. Preparation test plans about understanding and analysis around the football game can be seen in Table 1 .

TABLE I. ASPECTS OF UNDERSTANDING AND ANALYSIS OF FOOTBALL GAMES

\begin{tabular}{|c|c|}
\hline Aspect & Sub-aspect \\
\hline \multicolumn{2}{|l|}{ Scoring } \\
\hline \multirow{3}{*}{$\begin{array}{l}\text { Maintaining } \\
\text { control of the ball }\end{array}$} & Short and far operand \\
\hline & Control legs, thighs, chest \\
\hline & Supports ball carriers \\
\hline \multirow{2}{*}{$\begin{array}{l}\text { Striking out the } \\
\text { wicket }\end{array}$} & Shoot, close, flip \\
\hline & Uses a player's target \\
\hline \multirow{3}{*}{$\begin{array}{l}\text { Creating strike } \\
\text { space }\end{array}$} & Cross-over game overlapping running \\
\hline & The first operand, pass and run \\
\hline & Crossing game \\
\hline \multirow{3}{*}{ Using strike space } & Overlapping running \\
\hline & Dribbling, heading, depth-shielding \\
\hline & Timing run to wicket, close \\
\hline \multicolumn{2}{|l|}{ Prevents score } \\
\hline \multirow[b]{2}{*}{ Space defense } & Sweeping the ball \\
\hline & $\begin{array}{l}\text { Marking, pressing, guarding counterattacks, } \\
\text { slowing, closing, recovery runs }\end{array}$ \\
\hline Wicket defense & $\begin{array}{l}\text { Catch the ball, receive the ball, shot } \\
\text { stopping, share the ball }\end{array}$ \\
\hline \multirow[t]{2}{*}{ Win over the ball } & $\begin{array}{l}\text { In a position to catch, catch and throw the } \\
\text { ball }\end{array}$ \\
\hline & Tackling - blocking, dan sliding \\
\hline \multicolumn{2}{|l|}{ Starts the game } \\
\hline \multirow{2}{*}{$\begin{array}{l}\text { Throw in (strike } \\
\text { and defend) }\end{array}$} & Direct the throw \\
\hline & Looking for strategic positions • \\
\hline \multirow{2}{*}{$\begin{array}{lr}\text { Corner } & \text { kick } \\
\text { (strike } & \text { and } \\
\text { defend) } & \end{array}$} & Direct the kick \\
\hline & Occupy a strategic position \\
\hline \multirow{2}{*}{$\begin{array}{l}\text { Free kick (strike } \\
\text { and defend) }\end{array}$} & Direct the kick \\
\hline & Looking for strategic positions \\
\hline
\end{tabular}

\section{B. Football Playing Test}

Assessment of students' performance in playing football requires careful observations during the game. To assist teachers in observing and recording player's performance as the game progresses, Griffin, Oslin, \& Mitchell, have created an assessment instrument called the Game Performance Assessment Instrument (GPAI) [3]. Aspects observed in GPAI include behavior that reflects a player's ability to solve tactical problems in the game of football by making decisions, making movements that are appropriate to the demands of the game situation, implementing the type of skills chosen. The advantage of GPAI is that it is flexible. Physical education teachers can determine for themselves what components need to be observed that are adjusted to what is at the core of the lessons to be given at that time. For example, in football learning, physical education teachers only take a few components, such as decision making, skills execution, and support components-while the other components are considered sufficiently represented. Ideally in learning games, physical education teachers should take all the components, this will complete the ability of students to display the game. The details are in Table 2 below: 
between groups. Based on the analysis of the Independent Sample T-Test, the understanding variable obtained $t$ value of 1.64 and significant at $0.05(0.05 \leq 0.05)$ with a mean difference of -1.32 . This shows that there are significant differences between tactical and technical groups on understanding. Judging from the mean difference obtained by a difference of -1.32 , meaning that the tactical group proved to have a higher and significant effect than the technical group on student understanding. In other words, the implementation of the tactical approach influences students' understanding of football (First Hypothesis Accepted).

Whereas the variable in playing football skills obtained $t$ value of -5.71 and significant at $0.00(0.00 \leq 0.05)$ with a mean difference of -3.97 . This shows that there are significant differences between tactical and technical groups on football playing skills. Judging from the mean difference obtained by a difference of -3.97 , it means that the tactical group is proven to have a higher and significant effect than the technical group on football playing skills. In other words, the implementation of the tactical approach influences the basic skills of playing football students in football learning (the second hypothesis accepted).

\section{B. Discussion}

The purpose of this study is to examine the implementation of a tactical approach to understanding and skills in playing football. The results showed that the tactical group proved to have a higher and more significant effect than the technical group on student understanding. This means that the implementation of the tactical approach affects increasing student understanding in football learning. Summarized by O'Connor from several expert opinions concerning approaches that develop students' level of understanding, it is stated that the tactical approach is a learning model that aims to bring students to the initial situation of the game in the learning process to gain knowledge (declarative and procedural) through opportunities in decision making tactics [8]. Besides, Turner explained that game learning using the tactical approach model is an effective method of decision making in sports games, and should be used as the main objective in learning sports games [9].

The tactical approach emphasizes the appreciation of the game and tactical awareness as the basis for making decisions in the game and developing the skills needed [10]. In addition, Cushion explained that "the key to the learning approach in game sports lies in the tactic approach or Game sense [11]. Moreover, Allison \& Thorpe revealed several studies conducted by Stuart Allison and Rod Thorpe which added evidence that "tactical approaches are more effective in developing advanced physical education students than traditional skills approaches [12]. Furthermore, the implications of teaching a game through a tactic approach are (1) Developing critical understanding and effective responses to the reality and dynamics of the complexity of the situation and the development of a game, (2) Having a pedagogical character in constructing learning situations, (3) Describing the scope of broad learning strategies (such as critical thinking, interpersonal communication, reflective analysis, goal setting, cooperative learning, participatory experience, and problemunderstanding and playing football skills, therefore, independent sample t-test is performed to test the comparison 
[4] L.L. Grifin, S.A. Mitchel, and J.L. Oslin, Teaching Sport Concepts and Skills: A Tactical Games Approach (p. 8). USA: Human Kinetics Publishers, Inc., 1997.

). (4) If this tactical approach is a new physical education program, then a realistic game activity plan can be arranged together. (5) Physical education teachers need to provide opportunities for students to feel various positions in each learning game so that they are able to understand their role in the team. Through a tactical approach as a whole, students can learn to put themselves in all positions and develop the proper playing skills in their team in accordance with the rules of the game itself. (6) Activities in the form of tactical approaches can be used as a strategy in learning or training to be planned as a strategy for future game activities [13].

\section{CONCLUSION}

The implementation of tactical approaches influences students' understanding and basic skills in football learning.

\section{REFERENCES}

[1] L. Brown and S. Grineski, "Competition in Physical Education: An Educational Contradiction?," Journal of Physical Education, Recreation \& Dance, vol. 63(1), pp. 17-77, 1992.

[2] J.J. Prochaska, J.F. Sallis, D. Slymen, and T.L. McKenzie, "A longitudinal study of children's enjoyment of physical education," Pediatric, vol. 15, pp. 170, 2003.

[3] L.L. Griffin, J.L. Oslin, and S.A. Mitchell, "An analysis of two instructional approaches to teaching net games," Research Quarterly for Exercise and Sport, 1995.

[5] P. Werner, R. Thorpe, and D. Bunker, "Teaching games for understanding: Evolution of a model," Journal of Physical Education, Recreation \& Dance, vol. 67(1), pp. 28-33, 1996.

[6] S.A. Mitchell, "Improving invasion game performance," Journal of Physical Education, Recreation \& Dance, vol. 67(2), pp. 30-33, 1996.

[7] K. Gubacs-Collins, "Implementing a tactical approach through action research," Physical Education \& Sport Pedagogy, vol. 12(2), pp. 105126, 2007.

[8] J. O'Connor, The Teaching of Skills in Games and Sports, Monash University, 2006

[9] A.P. Turner, An Investigation Into Teaching Games For Understanding, University of North Carolina, 1995.

[10] R. Brooker, D. Kirk, S. Braiuka, and A. Bransgrove, "Implementing a Game Sense Approach to Teaching Junior High School Basketball in a Naturalistic Setting," European Physical Education Review, vol. 6(1), pp. 7-26, 2000.

[11] C.A. Cushion, Re-thinking teaching and coaching games. UK: Brunel University, 2002.

[12] S. Allison and R. Thorpe, "A Comparison of the Effectiveness of Two Approaches to Teaching Games Within Physical Education. A Skills Approach Versus a Games for Understanding Approach," British Journal of Physical Education, vol. 28(3), pp. 9-13, 1997.

[13] R. Light and R. Fawns, "The thinking body: Constructivist approaches to games teaching in physical education," Critical Studies in Education, vol. 42(2), pp. 69-87, 2001. 